\title{
NMR Metabolomics of Thrips (Frankliniella occidentalis) Resistance in Senecio Hybrids
}

\author{
Kirsten A. Leiss • Young H. Choi • \\ Ibrahim B. Abdel-Farid • Robert Verpoorte • \\ Peter G. L. Klinkhamer
}

Received: 28 May 2008 /Revised: 25 November 2008 / Accepted: 19 December 2008 / Published online: 24 January 2009

(C) The Author(s) 2009. This article is published with open access at Springerlink.com

\begin{abstract}
Western flower thrips (Frankliniella occidentalis) has become a key insect pest of agricultural and horticultural crops worldwide. Little is known about host plant resistance to thrips. In this study, we investigated thrips resistance in $F_{2}$ hybrids of Senecio jacobaea and Senecio aquaticus. We identified thrips-resistant hybrids applying three different bioassays. Subsequently, we compared the metabolomic profiles of these hybrids applying nuclear magnetic resonance spectroscopy (NMR). The new developments of NMR facilitate a wide range coverage of the metabolome. This makes NMR especially suitable if there is no a priori knowledge of the compounds related to herbivore resistance and allows a holistic approach analyzing different chemical compounds simultaneously. We show that the metabolomes of thrips-resistant and -susceptible hybrids differed considerably. Thrips-resistant hybrids contained higher amounts of the pyrrolizidine alkaloids (PA), jacobine, and jaconine, especially in younger leaves.
\end{abstract}

Electronic supplementary material The online version of this article (doi:10.1007/s10886-008-9586-0) contains supplementary material, which is available to authorized users.

K. A. Leiss $(\bowtie) \cdot$ P. G. L. Klinkhamer

Section Plant Ecology, Institute of Biology, Leiden University, Kaiserstraat 63,

2311GP Leiden, The Netherlands

e-mail: k.a.leiss@biology.leidenuniv.nl

Y. H. Choi $(\varangle) \cdot$ I. B. Abdel-Farid • R. Verpoorte Division of Pharmacognosy, Section Metabolomics, Institute of Biology, Leiden University,

2300 RA Leiden, The Netherlands

e-mail: y.choi@chem.leidenuniv.nl

\section{B. Abdel-Farid}

Botany Department, Aswan Faculty of Science,

South Valley University,

Aswan, Egypt
Also, a flavanoid, kaempferol glucoside, accumulated in the resistant plants. Both PAs and kaempferol are known for their inhibitory effect on herbivores. In resistant and susceptible $F_{2}$ hybrids, young leaves showed less thrips damage than old leaves. Consistent with the optimal plant defense theory, young leaves contained increased levels of primary metabolites such as sucrose, raffinose, and stachyose, but also accumulated jacaranone as a secondary plant defense compound. Our results prove NMR as a promising tool to identify different metabolites involved in herbivore resistance. It constitutes a significant advance in the study of plant-insect relationships, providing key information on the implementation of herbivore resistance breeding strategies in plants.

Keywords Senecio · Thrips (Frankliniella occidentalis) . NMR metabolomics · Pyrrolizidine alkaloids · Flavanoids . Jacaranone

\section{Introduction}

Over the last few decades, western flower thrips (Frankliniella occidentalis) has spread worldwide to become a key insect pest of agricultural and horticultural crops (Kirk and Terry 2003). There has been a massive increase in the international movement of plant material leading to the accidental transport of thrips. Thrips have many traits that predispose them to be successful invaders: small size, affinity for enclosed spaces, and high reproductive potential (Lawton and Brown 1986). In addition, western flower thrips is highly polyphagous infesting a wide range of about 200 wild and cultivated host species (Mantel and van de Vrie 1988). Thrips have piercing-sucking mouthparts, which enable them to feed on different types of plant cells (Hunter and Ullman 
1989). Feeding on actively growing tissue leads to distortion, reduction in plant growth, and eventually yields loss, while feeding on expanded tissue results in the characteristic silver leaf scars, which affect product appearance and reduce market quality (de Jager et al. 1995a). Western flower thrips causes indirect damage as the primary vector of tospoviruses (Maris et al. 2002).

Occurrence of host plant resistance to thrips is sparse and little is known about the underlying mechanisms. Morphological plant traits were not involved in resistance to western flower thrips in chrysanthemum (de Jager et al. 1995a). Instead, resistance was influenced by the chemical composition of host plants (de Jager et al. 1995b, 1996). Thrips preferentially feed on the older chrysanthemum leaves (de Jager et al. 1995a). No specific metabolites directly related to the resistance have yet been identified. Lately, a novel isobutylamide was suggested to be associated with host plant resistance to western flower thrips in chrysanthemum (Tsao et al. 2005). Overexpression of cysteine protease inhibitors in transgenic chrysanthemum was not related to thrips resistance (Annadana et al. 2002). In contrast, transgenic potato multidomain cysteine protease inhibitors were affiliated with thrips resistance (Outchkourov et al. 2004a, b).

Plant hybridization may drive the evolution of novel secondary plant metabolites (Rieseberg and Ellstrand 1993; Orians 2000) leading to enhanced resistance to herbivores and pathogens (Fritz 1999). In an earlier study of our group the metabolic profiles of Senecio jacobaea and Senecio aquaticus and their $F_{1}$ hybrids revealed multiple putative defense compounds (Kirk et al. 2005). This plant material was used to establish a $F_{2}$ hybrid generation to obtain independent segregation of defense characters. In this study, we investigated the differences in metabolites among thrips-resistant and -susceptible hybrids of the $F_{2}$ hybrid generation of $S$. jacobaea and $S$. aquaticus. We especially looked at metabolic differences among young and old leaves.

Plants produce a wide array of metabolites which play a significant role in their interactions with other organisms. The study of chemical host plant resistance has so far, for technical reasons, been limited to the identification of single compounds. However, as is generally the case in biological processes, it is very likely that not one but several compounds are involved in plant resistance, the identity of which is, a priori, unknown. One way to get round this problem is to use an analytical tool which allows the simultaneous detection of a wide range of metabolites, providing an instantaneous image of the metabolome of the resistant plant.

Nuclear magnetic resonance spectroscopy (NMR)-based metabolomics may be one of the methods which most fit this description, allowing the simultaneous detection of many different compounds, thus contributing to a deeper holistic approach (Verpoorte et al. 2007). So far, in the field of plant metabolomics, NMR has been successfully applied to study the effect of pathogen infection on host plants such as phytoplasmas in Catharanthus roseus (Choi et al. 2004) and tobacco mosaic virus in Nicotiana tabacum (Choi et al. 2006). The effect of herbivores on plants has been studied with NMR spectroscopy for chewing insects such as the caterpillars Plutella xylostella and Spodoptora exigua in Brassica rapa (Widarto et al. 2006).

We present the results of three different bioassays intended to identify thrips-resistant Senecio $F_{2}$ hybrids on which NMR-based metabolomics was subsequently applied to study the metabolic basis of resistance. NMR data were analyzed using diverse multivariate data analyses for comparison. Classification of data was validated by permutation tests.

\section{Methods and Materials}

Plant Materials Cuttings of 33 different $F_{2}$ hybrids of $S$. jacobaea and $S$. aquaticus derived from tissue culture were transplanted into $11 \mathrm{~cm}$ diameter pots filled with equal parts of dune sand and potting soil in spring 2005. Three clonal replicates of each $F_{2}$ hybrid were transferred to a growth chamber $\left(18: 6 \mathrm{~L} / \mathrm{D}, 20: 15^{\circ} \mathrm{C}\right)$ and grown for 6 weeks. To obtain resistant and susceptible genotypes, we subjected the $33 F_{2}$ hybrids to a thrips choice bioassay. We then selected the $F_{2}$ hybrids with the lowest and the highest thrips damage and confirmed their difference in resistance conducting a non-choice and a dual leaf disc bioassay. Plants of the susceptible and resistant $F_{2}$ hybrids for the bioassays as well as for NMR metabolomics were generated from tissue culture and grown as described above.

Thrips Bioassays-Whole Plant Choice Bioassay to Identify the Most Resistant and the Most Susceptible $F_{2}$ Hybrids In a fully randomized design, three clonal replicates of each $F_{2}$ hybrid were subjected to a thrips infestation with $F$. occidentalis, reared on chrysanthemum. According to van de Wetering et al. (1998), there are no significant differences in leaf area damaged between adult non-viruliferous male and female $F$. occidentalis of different ages. Per plant, ten adult thrips, two males and eight females, were used and left on the plants for 3 weeks. Thrips were directly released into the growth chamber by positioning a vial with $4 \times 10$ thrips on plant height in the center of four plants. Thrips does not cause growth damage in Senecio; therefore, only silver damage, expressed as the leaf area damaged in square millimeter, was visually scored per plant. The average of the three replicates was used to analyze differences in silver damage among the $F_{2}$ hybrids using a one-way 
ANOVA (Sokal and Rohlf 1995). Differences in silver damage among the third youngest and the third oldest leaf were tested with a paired samples $t$-test (Sokal and Rohlf 1995). Data of thrips damage were not normally distributed and were, therefore, $\ln$-transformed. To confirm the identification of thrips-resistant $F_{2}$ hybrids, we applied two more bioassays: the whole plant non-choice and the leaf disc dual choice bioassay.

Whole Plant Non-choice Bioassay One plant of each of the four most resistant and the four most susceptible $F_{2}$ hybrids were placed into individual thrips proof cages, consisting of plastic cylinders ( $80 \mathrm{~cm}$ height, $20 \mathrm{~cm}$ diameter), closed on both ends with displaceable rings of thrips proof gauze. The plants were arranged in a fully randomized design and to each cage ten adult western flower thrips were added and left for 3 weeks. Thereafter, silver damage, expressed as the leaf area damaged in square millimeter, was visually scored for each leaf. In order to investigate morphological and mechanical resistance, leaf age, hairiness, toughness, and dry weight were measured. Leaf age was counted in days, twice a week. Leaf hairiness and toughness were measured at the time of scoring for thrips damage. At two locations of each leaf the hairs per square centimeter were counted and the toughness was measured with a penetrometer. Averages per leaf were calculated. Plants were dried for 3 days in an oven at $50^{\circ} \mathrm{C}$ whereupon plant dry weight was measured for each leaf. Silver damage was not normally distributed. Silver damage per leaf was added up to analyze differences among resistant and susceptible hybrid plants with a Kruskall-Wallis test (Sokal and Rohlf 1995). To study the relationship between silver damage per leaf and leaf age, hairiness, toughness, and dry weight, correlations, using the non-parametric Kendall's tau $b$ correlation coefficient, were applied (Sokal and Rohlf 1995).

Leaf Disc Dual Choice Bioassay Dual choice assays were used to test the thrips preference of pairs of leaf discs from resistant versus susceptible $F_{2}$ hybrids as described by Outchkourov et al. (2004a). Leaf discs deriving from three different hybrid pairs were used. Pairs were matched at random. For each pair, the bioassay was repeated five times. Two leaf discs of $21 \mathrm{~mm}$ in diameter were punched from mature leaves at a similar position and placed on a thin layer of $1 \%$ water agar in a $9-\mathrm{cm}$ diameter Petri dish. A piece of filter paper $(5 \times 5 \mathrm{~mm})$ was positioned between the discs. Ten female $F$. occidentalis, which had been starved for one night, were shortly anesthetized with $\mathrm{CO}_{2}$, and placed on the filter paper. The Petri dishes were sealed with parafilm and placed in a growth chamber $(16: 8, \mathrm{~L} / \mathrm{D}$, $20: 20^{\circ} \mathrm{C}$ ). The number of thrips on each leaf disc was recorded at different time points after the start of the experiment up to $26 \mathrm{~h}$. As the repeated measurements were not independent, multiple time point measurements were averaged into an early ( $0-6 \mathrm{~h}$ after starting the experiment) and a late period (21-26 h after starting the experiment). Data were analyzed with a one-sided Wilcoxon signed rank test on the absolute differences of average numbers of thrips on the susceptible and resistant leaf discs (Sokal and Rohlf 1995).

Metabolomics-Extraction of Plant Material Ten plants each of the four most resistant and the four most susceptible $F_{2}$ hybrids, as identified in the three thrips bioassays, were used for NMR metabolomics. Plants were grown under standard conditions, described above, for 6 weeks. Each third leaf from above (young leaf) and each third leaf from below (old leaf) were taken for analysis. Each sample was ground under liquid $\mathrm{N}_{2}$ and freeze-dried. Freeze-dried plant material $(50 \mathrm{mg})$ was transferred to a $2-\mathrm{ml}$ microtube. Following a previous method (Choi et al. 2006), $1.5 \mathrm{ml}$ of a mixture of $\mathrm{KH}_{2} \mathrm{PO}_{4}$ buffer ( $\mathrm{pH}$ 6.0) in $\mathrm{D}_{2} \mathrm{O}$ and methanol- $d_{4}(1: 1)$ was used for the extraction of the plant samples.

For pyrrolizidine alkaloids extraction, a previously reported method was modified (Pieters et al. 1989). For this extraction, the ten replicates of each of the four thripsresistant and -susceptible hybrids were combined. Three replicates of this combination were analyzed for each hybrid. An amount of $100 \mathrm{mg}$ dried leaves was ultrasonicated for $30 \mathrm{~min}$ with dilute $\mathrm{H}_{2} \mathrm{SO}_{4}(0.5 \mathrm{M})$. After filtration, the filtrate was adjusted $\mathrm{pH} 9-10$ with $10 \%$ ammonium water and fractionated two times with $\mathrm{CHCl}_{3}$. The combined $\mathrm{CHCl}_{3}$ fractions were dried with $\mathrm{Na}_{2} \mathrm{SO}_{4}$ and evaporated to dryness. The dried extracts were dissolved in $\mathrm{CDCl}_{3}$ containing $0.447 \mu \mathrm{mol} / \mathrm{ml}$ of hexamethyldisiloxane (HMDSO).

NMR Analysis NMR spectra were recorded at $25^{\circ} \mathrm{C}$ on a $600 \mathrm{MHz}$ Bruker DMX-600 spectrometer (Bruker, Karlsruhe, Germany) operating at a proton NMR frequency of $600.13 \mathrm{MHz}$. MeOH- $d_{4}$ was used as the internal lock. Each ${ }^{1}$ H-NMR spectrum consisted of 256 scans requiring $8 \mathrm{~min}$ and $30 \mathrm{~s}$ acquisition time with the following parameters: $0.12 \mathrm{~Hz} /$ point, pulse width (PW) of $30(11.3 \mu \mathrm{s})$, and relaxation delay (RD) of $2 \mathrm{~s}$. A pre-saturation sequence was used to suppress the residual $\mathrm{H}_{2} \mathrm{O}$ signal with low power selective irradiation at the $\mathrm{H}_{2} \mathrm{O}$ frequency during the recycle delay. Free induction decay was Fourier-transformed with a line broadening factor of $0.3 \mathrm{~Hz}$. The resulting spectra were manually phased and baseline corrected, and calibrated to the internal standard trimethyl silyl propionic acid sodium salt (TMSP) at $0.0 \mathrm{ppm}$ using XWIN NMR (version 3.5, Bruker). The parameters of 2D NMR experiments such as J-resolved, COSY, HSQC, and HMBC were the same as those of our previous reports (Choi et al. 2006). 
Table 1 Silver damage (square millimeter) of the four most resistant and the four most susceptible Senecio $F_{2}$ hybrid lines

\begin{tabular}{lcc}
\hline & Hybrid & Silver damage \\
\hline Resistant & 217 & $8 \pm 5$ \\
& 115 & $12 \pm 5$ \\
& 119 & $16 \pm 6$ \\
& 206 & $37 \pm 18$ \\
Susceptible & 108 & $275 \pm 80$ \\
& 204 & $288 \pm 132$ \\
& 221 & $307 \pm 60$ \\
& 114 & $349 \pm 167$ \\
\hline
\end{tabular}

Data are means and standard errors of three replicates

For 1D and 2D NMR analysis of pyrrolizidine alkaloids, the same parameters were used without pre-saturation of water. Calibration was performed on residual $\mathrm{CDCl}_{3}$ signal at $\delta 7.26$.

Data Analysis Spectral intensities of ${ }^{1} \mathrm{H}-\mathrm{NMR}$ spectra were scaled to the intensity of the internal standard (TMSP, $0.05 \% w / v)$ and reduced to integrated regions of equal width (0.04) corresponding to the region of $\delta 0.4-\delta 10.0$. The regions of $\delta 4.8-\delta 4.9$ and $\delta 3.28-\delta 3.40$ were excluded from the analysis because of the residual signal of water and $\mathrm{MeOH}$. Principal component analysis (PCA) and partial least square-discrimination analysis (PLS-DA) were performed with the SIMCA-P software (v. 11.0, Umetrics, Umeå, Sweden). The scaling method for PCA was Pareto and for PLS-DA the unit-variance method. ANOVA, hierarchical clustering analysis, and $t$ tests were performed by MultiExperiment Viewer (v. 4.0; Saeed et al. 2003).
PLS-DA models were validated by using the permutation method through 20 applications, which is a default validation tool in the software package applied (SIMCAP). Variance $\left(R^{2}\right)$ and cross-validated variance values (predictive ability of the model, $Q^{2}$ ) of PLS-DA using five components were calculated.

\section{Results}

Whole Plant Choice Bioassay The $F_{2}$ hybrids differed significantly in thrips damage (ANOVA, $F=3.17, d f=32$, $P<0.001$ ). In the most resistant hybrid, an $8 \mathrm{~mm}^{2}$ leaf area was affected by silver damage compared to $349 \mathrm{~mm}^{2}$ in the most susceptible hybrid. Young leaves had significantly less silver damage compared to mature leaves ( $t$-test, $t=$ 5.87, $d f=32, P<0.001)$. Of these $33 F_{2}$ hybrids, the four most resistant and the four most susceptible ones (Table 1) were chosen for further testing in a whole plant non-choice and a leaf disc dual choice bioassay.

Whole Plant Non-choice Bioassay The four thrips-resistant $F_{2}$ hybrids, described in the above whole plant choice bioassay, had significantly (Kruskall-Wallis test, $\chi^{2}=5.33$, $d f=1, P=0.029)$ less thrips damage per plant $\left(94 \mathrm{~mm}^{2}\right)$ compared to the four susceptible hybrids $\left(368 \mathrm{~mm}^{2}\right)$. The results of the plant choice and the non-choice bioassay were thus completely compatible. Resistant $F_{2}$ hybrids had on average 15 and susceptible ones 13 leaves, respectively $(t$ test, $t=1.55, d f=6, P=0.17)$. Silver damage was for all four resistant and all four susceptible $F_{2}$ hybrids significantly

Table 2 Correlations (Kendall's tau) between silver damage (square millimeter) per leaf and morphological (leaf age) as well as mechanical (toughness, hairiness, and dry weight) resistance factors of four thrips-resistant and four thrips-susceptible Senecio $F_{2}$ hybrid lines

\begin{tabular}{|c|c|c|c|c|c|}
\hline & Hybrid & Leaf age & Toughness & Hairiness & Dry weight \\
\hline \multirow[t]{8}{*}{ Resistant } & 217 & 0.734 & -0.354 & -0.743 & 0.559 \\
\hline & $N=13$ & $P=0.003 * *$ & $P=0.167$ & $P=0.003 * *$ & $P=0.022 *$ \\
\hline & 115 & 0.716 & 0.279 & -0.750 & 0.716 \\
\hline & $N=10$ & $P=0.007 * *$ & $P=0.321$ & $P=0.005^{*} *$ & $P=0.007 * *$ \\
\hline & 119 & 0.552 & -0.327 & -0.331 & 0.378 \\
\hline & $N=15$ & $P=0.008^{* *}$ & $P=0.162$ & $P=0.115$ & $P=0.072$ \\
\hline & 206 & 0.597 & -0.166 & -0.597 & 0.464 \\
\hline & $N=14$ & $P=0.011^{*}$ & $P=0.519$ & $P=0.011^{*}$ & $P=0.048^{*}$ \\
\hline \multirow[t]{8}{*}{ Susceptible } & 114 & 0.671 & -0.379 & -0.739 & 0.648 \\
\hline & $N=14$ & $P=0.001 * *$ & $P=0.075$ & $P=0.000 * * *$ & $P=0.002^{* *}$ \\
\hline & 221 & 0.726 & 0.322 & -0.658 & 0.393 \\
\hline & $N=14$ & $P=0.002^{*} *$ & $P=0.188$ & $P=0.005^{* *}$ & $P=0.093$ \\
\hline & 204 & 0.664 & -0.252 & -0.503 & 0.554 \\
\hline & $N=16$ & $P=0.002^{* *}$ & $P=0.249$ & $P=0.021 *$ & $P=0.008^{* *}$ \\
\hline & 108 & 0.486 & -0.039 & -0.299 & 0.505 \\
\hline & $N=15$ & $P=0.014^{*}$ & $P=0.854$ & $P=0.132$ & $P=0.011^{*}$ \\
\hline
\end{tabular}

$N$ indicates the number of leaves the correlation is based on 

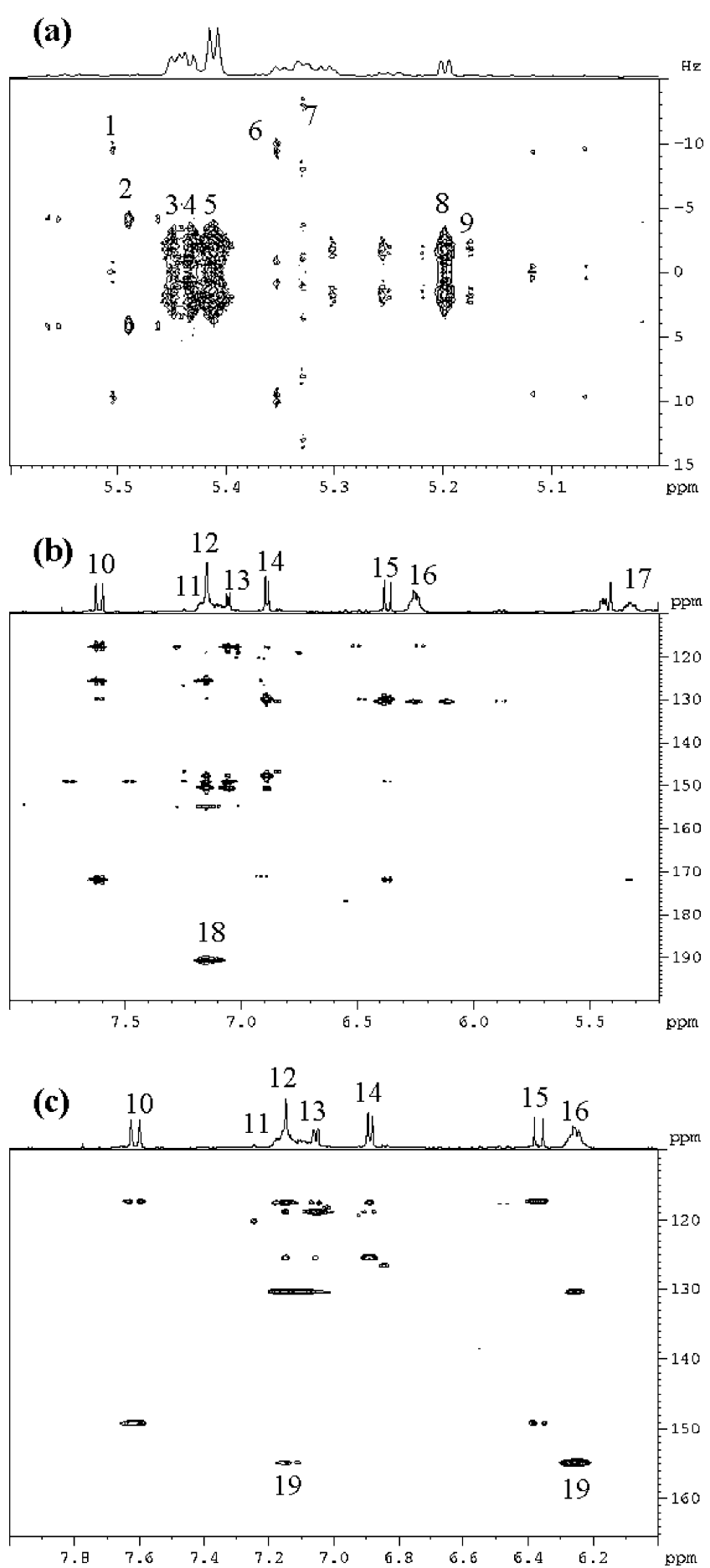

Fig. 1 Typical 2D J-resolved NMR spectrum (a), HMBC (b), and HSQC-TOCSY (c) of Senecio $F_{2}$ hybrids. 1, H-3 of feruloyl quinic acid; 2, $\mathrm{H}-1^{\prime}$ of kaempferol glucoside; $3 \mathrm{H}-1^{\prime}$ of stachynose; $4, \mathrm{H}-1^{\prime}$ of raffinose; $5, \mathrm{H}-1$ of sucrose; $6, \mathrm{H}-3$ of 3-O-caffeoyl quinic acid; 7, $\mathrm{H}-5$ of chlorogenic acid; $8, \mathrm{H}-1$ of $\alpha$-glucose; $9, \mathrm{H}-1$ of trehalose; $10, \mathrm{H}-7$ of chlorogenic acid; $11, \mathrm{H}-3$ and $\mathrm{H}-5$ of jacaranone; $12, \mathrm{H}-2^{\prime}$ of chlorogenic acid; $13, \mathrm{H}-6^{\prime}$ of chlorogenic acid; 14, H-5' of chlorogenic acid; $15, \mathrm{H}-8^{\prime}$ of chlorogenic acid; $16, \mathrm{H}-2$ and $\mathrm{H}-6$ of jacaranone; 17 , $\mathrm{H}-5$ of chlorogenic acid; 18 , correlation between $\mathrm{H}-3, \mathrm{H}-5$, and C-4 of jacaranone; 19, correlation between $\mathrm{H}-2, \mathrm{H}-3, \mathrm{H}-5, \mathrm{H}-6$, and $\mathrm{C}-1$ of jacaranone positively correlated to leaf age (Table 2). None of the morphological and mechanical factors was related to thrips resistance.

Leaf Disc Dual Choice Bioassay In all three pairs of leaf discs of resistant versus susceptible $F_{2}$ hybrids, the number of thrips in the early (0-6 h after start of the experiment) period was significantly lower on the leaf disc of the resistant hybrid (Wilcoxon signed rank test, $P=0.028$; $0.042 ; 0.018)$. For two out of the three leaf pairs, this was true for the late period $(21-26 \mathrm{~h}$ after starting the experiment) as well (Wilcoxon signed rank test, $P=0.043$; 0.046; 0.715).

Application of the $1 D$ and $2 D N M R$ Spectroscopy for Elucidation of Metabolites The ${ }^{1} \mathrm{H}-\mathrm{NMR}$ spectra of plant extracts always give congested signals. In our previous work, 2D J-resolved spectra were successfully applied to overcome the signal overlapping (Choi et al. 2006). Indeed, by applying J-resolved spectra in this study, the signals of flavanoid glycosides, raffinose, stachyose, and sucrose were clearly resolved (Fig. 1a). In the aromatic region, two isomeric phenylpropanoids, 3-Ocaffeoyl quinic acid and 5-O-caffeoyl quinic acid (chlorogenic acid), as well as feruloyl quinic acid, were identified using 2D NMR spectra including COSY, HSQC, and HMBC. These metabolites were confirmed by comparison with reference compounds and reported data (Choi et al. 2006). In addition to phenylpropanoids, there were two major signals at $\delta 6.25$ and $\delta 7.15$, which correlated with each other in the COSY spectrum. Using HMBC and HSQC-TOCSY spectra, those two signals at $\delta 6.25$ and $\delta$ 7.15 were assigned as $\mathrm{H}-2$ and $\mathrm{H}-6$, and $\mathrm{H}-3$ and $\mathrm{H}-5$ of jacaranone, respectively (Fig. 1b, c). The characteristic chemical shifts and the structures of the metabolites of Senecio $F_{2}$ hybrid leaves detected in the ${ }^{1} \mathrm{H}-\mathrm{NMR}$ spectra are shown in Fig. 2 and Table S1.

Principal Component Analysis and Partial Least Square Regression-Discriminant Analysis of ${ }^{1} \mathrm{H}-\mathrm{NMR}$ Data

Among multivariate data analyses, the most common unsupervised method is principal component analysis (PCA). Thus, as the first step of multivariate data analysis PCA was performed on the bucketed dataset to discriminate the samples. For the dataset obtained from the ${ }^{1} \mathrm{H}-\mathrm{NMR}$ analysis, a 22-component model explained $98.5 \%$ of the variance, with the first two components explaining $70.7 \%$. However, as shown in Fig. 3a, there was no separation among resistant and susceptible Senecio $F_{2}$ hybrids. Instead, developmental stage was a key separating factor that led to a clear discrimination among young and old leaves. According to the loading plot, the levels of citric and malic acid were higher in old leaves whereas those of 
Fig. 2 Chemical structures of some metabolites identified in the NMR spectrum of Senecio $F_{2}$ hybrids

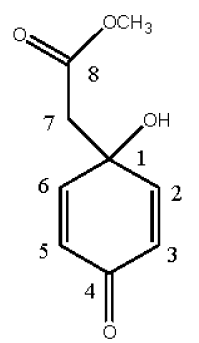

jacaranone<smiles>[2H]c1c(-c2ccc(O)cc2)oc2cc(O)cc(O)c2c1=O</smiles>

$\mathrm{R}=\mathrm{OH}$, kaempferol

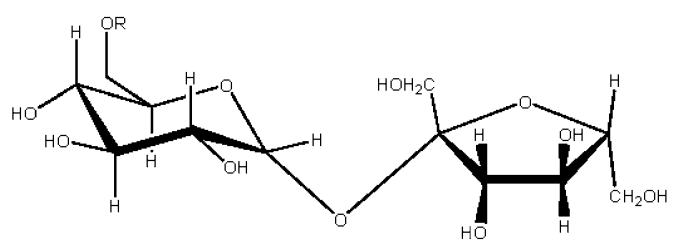

$\mathrm{R}=\mathrm{H}$, sucrose

$\mathrm{R}=\alpha$-D-galactopyranosyl $(1 \rightarrow 6)$, raffinose

$\mathrm{R}=\alpha$-D-galactopyranosyl $(1 \rightarrow 6), \alpha$-D-galactopyranosyl $(1 \rightarrow 6)$, stachyose

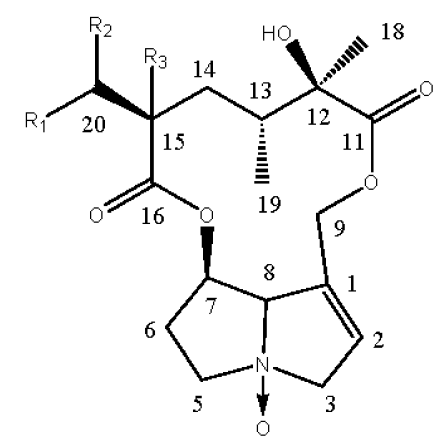

$\mathrm{R}_{1}=\mathrm{H}, \mathrm{R}_{2}=\mathrm{R}_{2}=-\mathrm{O}-$, jacobine- $N$-Oxide

$\mathrm{R}_{1}=\mathrm{Cl}, \mathrm{R}_{2}=\mathrm{H}, \mathrm{R}_{3}=\mathrm{OH}$, jaconine- $N$-Oxide

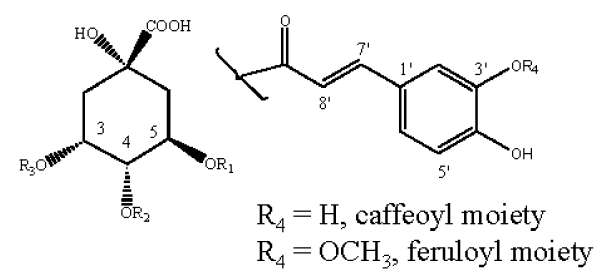

$\mathrm{R}_{1}=$ caffeoyl, $\mathrm{R}_{2}=\mathrm{R}_{3}=\mathrm{H}$, chlorogenic acid

$\mathrm{R}_{1}=\mathrm{H}, \mathrm{R}_{2}=\mathrm{H}, \mathrm{R}_{3}=$ caffeoyl, 3-O-caffeoylquinic acid

$\mathrm{R}_{1}=\mathrm{H}, \mathrm{R}_{2}=\mathrm{H}, \mathrm{R}_{3}=$ feruloyl, 3-O-feruloyllquinic acid sucrose, raffinose, and stachyose as well as jacaranone accumulated more in young leaves (Fig. 3b).

In the dataset employed, the difference among resistant and susceptible leaves seemed to be smaller than among developmental stages. The large metabolic difference in developmental stages compared to the difference among resistant and susceptible plants was confirmed by hierarchical analysis (HCA, Fig. S1). Prior to HCA, the statistically significant signals were selected applying ANOVA. From $239{ }^{1} \mathrm{H}-\mathrm{NMR}$ signals 161 were significant $(P<0.05)$. The ANOVA was based on one factor containing four groups: resistant young leaves, susceptible young leaves, resistant old leaves, and susceptible old leaves. Two additional sets of $t$ tests, one for young and one for old leaves comparing resistant and susceptible plants were conducted $(P<0.05)$. These tests showed that for young leaves, 56 signals out of 239, and for old leaves, 25 signals out of 239 , were related to thrips resistance. In $\mathrm{HCA}$, the leaves of the same age were closely clustered but the metabolic resemblance within resistant or susceptible plants was scattered. In order to distinguish resistant leaves from susceptible ones, analysis was extended to PLS-DA, a supervised multivariate data technique.

PLS-DA uses a discrete class matrix (0 and 1) as an additional matrix. In contrast to PCA that only uses the information of the metabolomic matrix, PLS-DA also takes into account the resistance matrix. The separation of PLSDA is achieved by the covariance of the two datasets. When PLS-DA was applied the separation of thripsresistant and -susceptible plants considerably improved (Fig. 4a). Validation of the PLS-DA model by permutation tests resulted in a variance $R^{2}$ of 0.74 and a cross-validated variance $Q^{2}$ of 0.61 . All $Q^{2}$ values of the permuted $Y$ vectors were lower than the original ones and the regression of $Q^{2}$ lines intersected at below zero (Fig. 4c, d). 
(a)

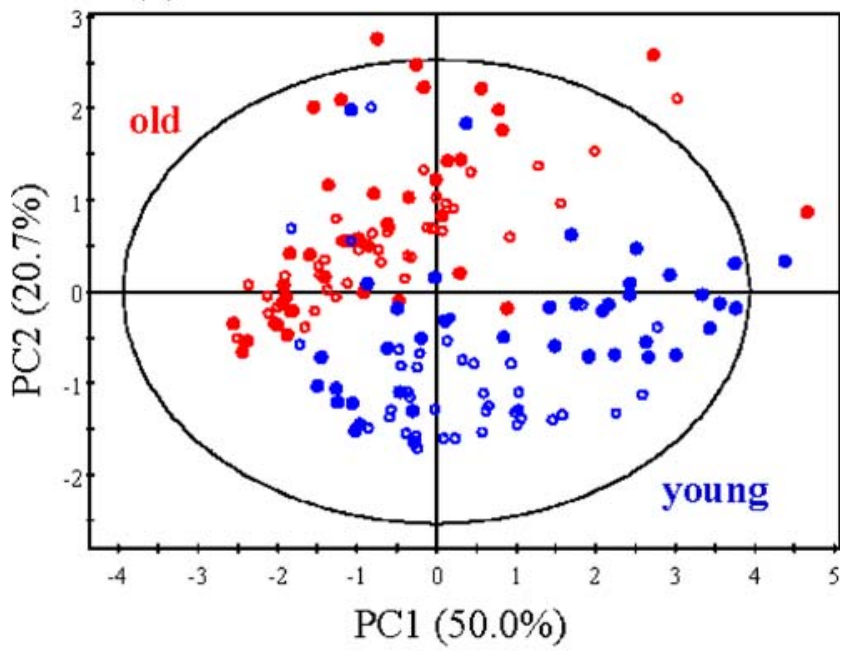

(b)

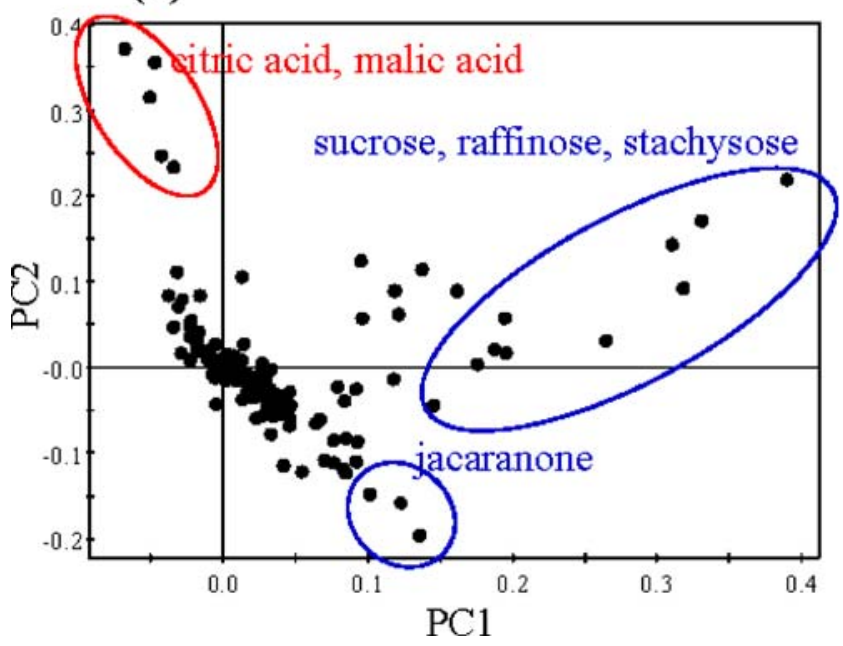

Fig. 3 Score (a) and loading plot (b) of principal component analysis based on ${ }^{1} \mathrm{H}-\mathrm{NMR}$ spectra of Senecio $F_{2}$ hybrid genotypes. Filled red circle, old leaves of thrips-resistant genotypes $(n=40)$; filled blue circle, young leaves thrips-resistant genotypes $(n=40)$; empty red circle, old leaves of thrips-susceptible genotypes $(n=40)$; empty blue circle, young leaves of thrips-susceptible genotypes $(n=40)$. The ellipse represents the Hotelling T2 with $95 \%$ confidence in score plots

Irrespective of leaf age, resistant and susceptible $F_{2}$ hybrids were clearly clustered. The loading plot indicated that methyl signals of pyrrolizidine alkaloids (PAs) at $\delta 1.12$ (H-19), $\delta 1.24$ (H-21), and $\delta 1.36(\mathrm{H}-18$; Pieters et al. 1989) were distinguishably higher in the resistant plants. Also, the anomeric proton of kaempferol glucoside at $\delta 5.50-\delta 5.60$ together with H-6 and H-8 of the glycoside around at $\delta 6.30$ increased in the Senecio $F_{2}$ hybrids resistant to thrips (Fig. 4b). Only total PA could be determined by the methyl signals detected. Therefore, more evidence for the PAs, e.g., the signals of pyrrolizidine moiety, was required to identify specific compounds. The characteristic $\mathrm{H}-2$ signal of the pryrrolizidine moiety is generally detected around at $\delta$ $6.0-\delta 6.2$. However, this region overlaps with the signals of jacaranone and chlorogenic acid. For the confirmation and quantification of individual PAs, we applied an acid-base extraction followed by NMR metabolomic profiling. For the acid-base extraction the ten replicates of each of the four thrips-resistant and -susceptible hybrids were mixed and three replicates of these used for the analysis.

Elucidation and Quantitation of Pyrrolizidine Alkaloids Using Acid-Base Extraction Followed by Quantitative ${ }^{1} \mathrm{H}$ NMR The ${ }^{1} \mathrm{H}-\mathrm{NMR}$ spectrum of the alkaloid extract, obtained by the acid-base extraction, showed two major $\mathrm{PAs}$, jacobine and jaconine $\mathrm{N}$-oxide. The $\mathrm{N}$-oxides were confirmed by the unambiguous down field shifts $(0.4$ $0.7 \mathrm{ppm}$ ) of the signals of $\mathrm{H}-3, \mathrm{H}-5$, and $\mathrm{H}-8$ adjacent to the $\mathrm{N}$-oxide functional group when compared with the free bases (Pieters et al. 1989; Witte et al. 1992). For the final structure confirmation, COSY, TOCSY, HSQC, and HMBC spectra were employed (Fig. S2).

The ${ }^{1} \mathrm{H}-\mathrm{NMR}$ signals are always proportional to the molar concentrations. In the crude alkaloid extract, $\mathrm{H}-2$ was detected in a non-crowded region, separated from other ones. These signals were used for quantification comparing them to the intensity of the internal standard, HMDSO $(0.48 \mu \mathrm{mol} / \mathrm{ml})$. As confirmed by the PLS-DA results, young and old leaves of thrips-resistant $F_{2}$ hybrids accumulated more PA N-oxide (Fig. 5). Old ( $t$-test, $d f=22$, $P<0.001)$ and young $(t$-test, $d f=22, P<0.001)$ leaves of thrips-resistant hybrids contained significantly more jacobine N-oxide. Younger leaves of thrips-resistant hybrids also accumulated significantly more jaconine $\mathrm{N}$-oxide $(t-$ test, $d f=22, P=0.005)$. The difference of jaconine N-oxide in old leaves was close to significance ( $t$-test, $d f=22, P=$ 0.008). Young leaves in both resistant and susceptible hybrids accumulated more jacobine $\mathrm{N}$-oxide (resistant hybrids: $t$-test, $d f=22, P<0.001$; susceptible hybrids: $t$-test, $d f=22, P<0.001$ ) and more jaconine N-oxide (resistant hybrids: $t$-test, $d f=22, P<0.001$; susceptible hybrids: $t$-test, $d f=22, P<0.001)$.

\section{Discussion}

NMR proved to be successful in the simultaneous detection of different metabolites potentially involved in thrips resistance. The metabolomic profiles of thrips-resistant and -susceptible hybrids differed considerably. Thripsresistant $F_{2}$ hybrids showed significantly higher amounts of the PAs, jaconine and jacobine $\mathrm{N}$-oxide, and a flavanoid, kaempferol glucoside.

PAs have been well studied in the Senecio species and are regarded as constitutive defense against generalist 
A
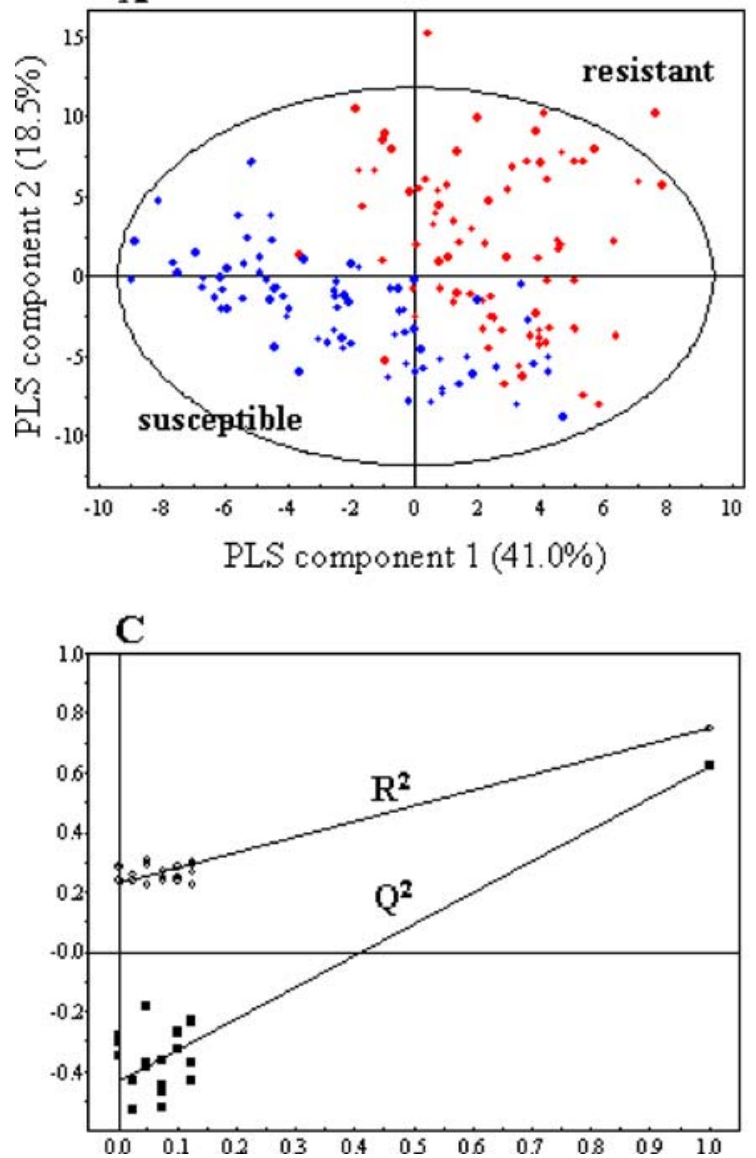

Fig. 4 Score (a), loading plot (b), and permutation validation plot of resistant (c) and susceptible group (d) of partial least square regression-discriminant analysis based on ${ }^{1} \mathrm{H}-\mathrm{NMR}$ spectra of Senecio $F_{2}$ hybrid genotypes. Filled red circle, old and young leaves of thrips-
B

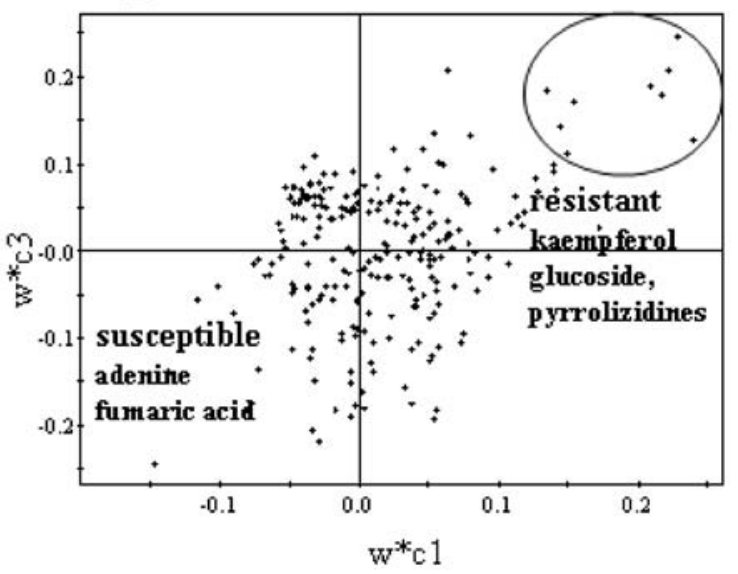

D

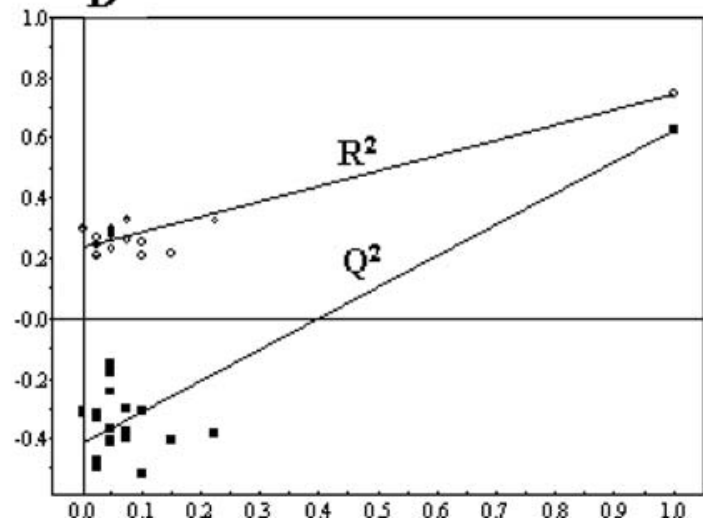

resistant genotypes $(n=80)$; filled blue circle, old and young leaves thrips-susceptible genotypes $(n=80)$. The ellipse represents the Hotelling T2 with $95 \%$ confidence in score plots herbivores. They deter chewing insects such as caterpillars (Bentley et al. 1984; van Dam et al. 1995), locusts (Macel et al. 2005), and beetles (Hägele and Rowell-Rahier 2000). PAs also have a negative effect on sucking insects such as aphids (Vrieling et al. 1991; Macel et al. 2005). So far, no inhibitory influences of PAs on thrips have been detected. Plants of $S$. jacobaea with and without Haplothrips senecionis, a specialist on Senecio species, did not yield any difference in total PA concentration (Vrieling et al. 1991). In vitro tests studying the effect of different PAs on the development of first instar larvae of the generalist $F$. occidentalis showed a significantly reduced larval survival at $10 \times$ plant concentrations but not at $1 \times$ plant concentrations (Macel et al. 2005). Neither jaconine nor jacobine were included in these in vitro tests. However, a significantly lower amount of thrips damage on the jacobine compared to the erucifoline chemotype of $S$. jacobaea (Macel 2003) confirms our results. Furthermore, PAs are stored in the cell vacuoles (Ehmke et al. 1988), which are ingested by the thrips being cell feeders. Both PAs, jaconine and jacobine, were present in higher concentrations in young leaves compared to the old ones. Concurrently, young leaves showed significantly less thrips damage. This is in accordance with the finding that in Senecio species, young leaves have relatively high concentrations of PAs compared to old leaves (Hartmann and Zimmer 1986; de Boer 1999). The more valuable plant parts are better defended against generalist herbivores than less important organs as is predicted by the optimal defense theory (Zangerl and Bazzaz 1992; van Dam et al. 1996).

Flavanoids are generally involved in plant resistance to herbivores (Bennett and Wallsgrove 1994). The presence of kaempferol in the Senecio $F_{2}$ hybrids confirms the findings of Kirk et al. (2005) reporting kaempferol for the first time in Senecio species. Kaempferol is known to convey a deterrent effect on generalist caterpillars (Onyilagha et al. 2004). Aphid resistant cow pea lines contained significantly higher amounts of flavanoids, including kaempferol, compared to 
(a)

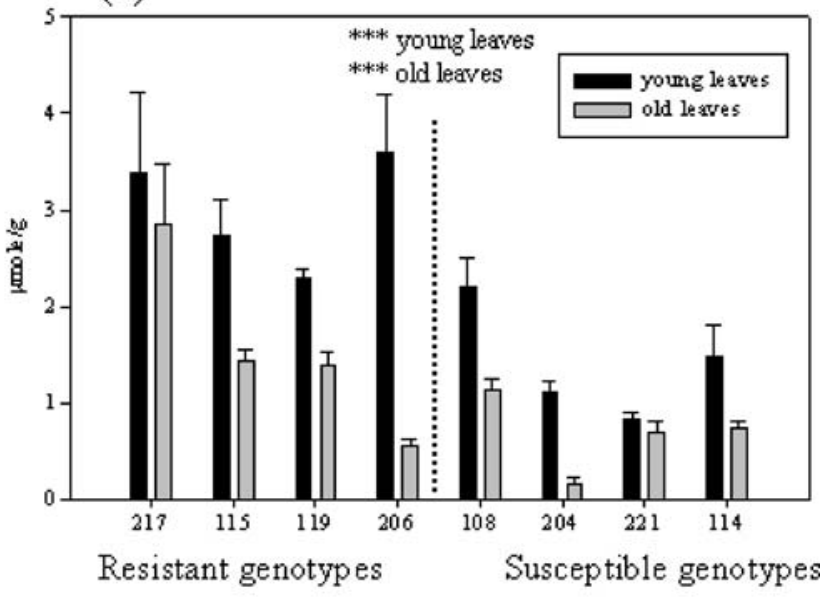

(b)

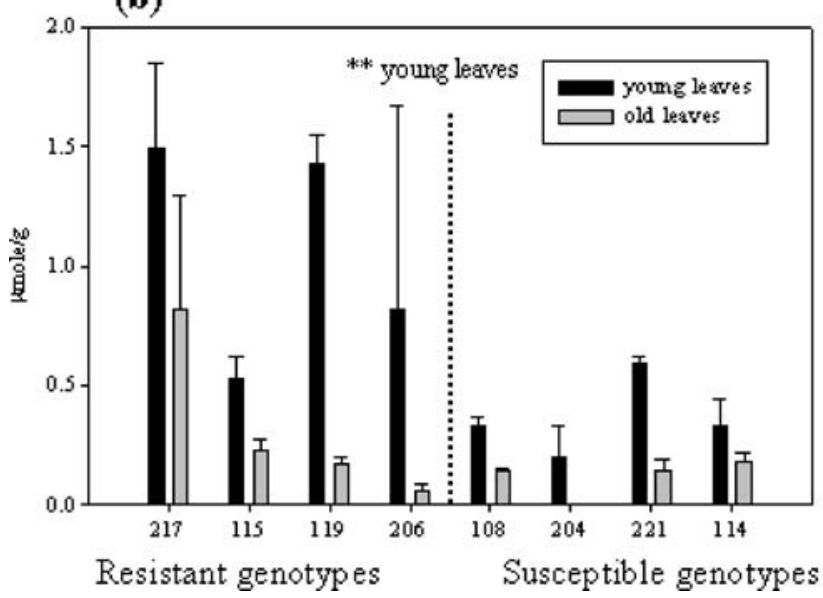

Fig. 5 Yields (mol/g) of jacobine $\mathrm{N}$-oxide (a) and jaconine N-oxide (b) for young and old leaves of thrips-resistant and -susceptible Senecio $F_{2}$ hybrids obtained by quantitative ${ }^{1} \mathrm{H}-\mathrm{NMR}$ analysis. Data are based on the combination of the ten replicates of each of four thrips-resistant and -susceptible hybrids, of which three replicates were analyzed per hybrid. Means and their standard deviation are presented. Data were analyzed by $t$ tests. Significant differences in PAs between thrips-resistant and -susceptible hybrids are designated by $* * * P<0.001$ and $* * P<0.01$. Young leaves contained significantly higher amounts of both PAs in resistant and susceptible hybrids (all $t$ tests $d f=22, P<0.001$ )

susceptible lines (Lattanzio et al. 2000). Recently, kaempferol has been identified to confer resistance to onion thrips (Thrips palmi) in golden rod (Solidago altissima; Wu et al. 2007). Like western flower thrips, onion thrips is a polyphagous worldwide pest, which causes significant economic losses (Kirk and Terry 2003).

Besides the PAs and flavanoids, specifically involved in thrips resistance, three other phenolic compounds involved in plant-herbivore interactions, 3-O-caffeoyl acid and 5-Ocaffeoyl quinic acid (chlorogenic acid, CGA), and feruloyl quinic acid (FQA), were identified to be present in the metabolome of the Senecio $F_{2}$ hybrids. CGA has been described as an anti-feedant and digestibility reducer in different caterpillar species (Mallikarjuna et al. 2004; Johnson and Felton 2001; Simmonds and Stevenson 2001) and sucking insects such as aphids (Miles and Oertli 1993). FQA has been implicated in the resistance of sucking herbivores such as cereal aphids (Cabrera et al. 1995; Havlickova et al. 1996) and cereal midges (Ding et al. 2000; Abdel-Aal et al. 2001). FQA is a precursor of lignin conferring rigidity to cell walls (Bennett and Wallsgrove 1994). As such, it is linked to the resistance against stem borers in maize (Santiago et al. 2006; Mao et al. 2007) and cotton (Wang et al. 2006).

As expected, the young leaves of the Senecio $F_{2}$ hybrids, being photosynthetically more active, contained more primary metabolites such as sugars, compared to older leaves. They are, therefore, more attractive to herbivores and pathogens. To defend these valuable plant parts, they do contain more secondary metabolites related to plant defense. Next to the increased amount of PAs in the young leaves of the thrips-resistant Senecio $F_{2}$ hybrids, young leaves in general contained more jacaranone. Analogues of jacaranone are known to occur in different Senecio species (Lajide et al. 1996; Xu et al. 2003; Kirk et al. 2005). They have shown insecticidal activity against houseflies (Xu et al. 2003) and inhibited growth in the generalist herbivore Spodoptera litturalis (Lajide et al. 1996).

Our approach to apply NMR as a technique to identify metabolites differing between thrips-resistant and -susceptible plants proved to be very successful. NMR indicated three different metabolites as potential candidates for thrips resistance. While the PAs due their toxic effect on mammals (Cheeke 1988) may be interesting in developing thrips resistance in ornamentals, kaempferol and jacaranone are very promising candidates to develop host plant resistance to thrips in crops. Not only do they inhibit thrips but they also produce positive effects on human health. Jacaranone has been investigated as a potential anti-cancer agent (Loizzo et al. 2007). Flavanoids in general caused a significant extension of life span in cancer-susceptible mice (Butelli et al. 2008), while kaempferol in particular demonstrated a cytotoxic activity on human cancer cell lines (Daniela et al. 2007; Li et al. 2007). A tomato with increased amounts of flavanoids, whereby kaempferol glycoside accounted for $60 \%$ of this increase, has already been engineered (Le Gall et al. 2003).

Applying NMR to the study of herbivore resistance constitutes a significant advance in the study of plantinsect relationships, providing key information on the implementation of herbivore resistance breeding strategies in plants.

Acknowledgments We thank Victoria Twist for critically reviewing the English of the manuscript. The research was supported by SenterNovem, an agency of the Dutch Ministry of Economic affairs (grant no. ISH5078). 
Open Access This article is distributed under the terms of the Creative Commons Attribution Noncommercial License which permits any noncommercial use, distribution, and reproduction in any medium, provided the original author(s) and source are credited.

\section{References}

AbDel-Aal, E. S. M., Hucl, P., Sosluski, F. W., Graf, R., Gillot, C., and PIETRZAK, L. 2001. Screening spring wheat for midge resistance in relation to ferulic acid content. J. Agric. Food Chem. 49:3559-3566. doi:10.1021/jf010027h.

Annadana, S., Kuiper, G., Visser, P. B., De Kogel, W. J., UDAYAKUMAR, M., and JONGSMA, M. A. 2002. Expression of potato multicystatin in florets of chrysanthemum and assessment of resistance to western flower thrips, Frankliniella occidentalis. Acta Hortic. 572:121-129.

Bennett, R. N., and Wallsgrove, R. M. 1994. Tansley Review No. 72 secondary metabolites in plant defence mechanisms. New Phytol. 127:617-633. doi:10.1111/j.1469-8137.1994.tb02968.x.

Bentley, M. D., LeONARD, D. E., StodDard, D. E., and ZALKOW, L. H. 1984. Pryrolozidine alkaloids as larval feeding deterrents for spruce budworm, Choristoneura fumiferana (Lepidoptera: Tortiricidae). Ann. Entomol. Soc. Am. 77:393-397.

Butelli, E., Titta, L., Giorgio, M., Mock, H.-P., Matros, A., Peterek, S., SchiJlen, E. G. W. M., Hall, R. D., Bovy, A. G., LUO, J., and MARTIN, C. (2008) Enrichment of tomato fruit with health-promoting anthocyanins by expression of select transcription factors. Nat. Biotechnol. 26:1301-1308. advance online publication

Cabrera, H. M., Munoz, O., Zuniga, G. E., Corcuera, L. J., and ArgandonA, V. H. 1995. Changes in ferulic acid and lipid content in aphid-infested barley. Phytochem. 39:1023-1026. doi:10.1016/0031-9422(95)00065-F.

CHEeKe, P. R. 1988. Toxicity and metabolism of pyrrolizidine alkaloids. J. Anim. Sci. 66:2343-2350.

Choi, Y. H., TAPiAs, E. C., KiM, H. K., LefEBer, A. W. M., ERKELNS, C., Verhoeven, J. T. J., Brzin, J., Zel, J., and Verpoorte, R. 2004. Metabolic discrimination of Catharanthus roseus leaves infected by phytoplasma using ${ }^{1} \mathrm{H}-\mathrm{NMR}$ spectroscopy and multivariate data analysis. Plant Physiol. 135:2398-2410. doi:10.1104/pp.104.041012.

Choi, Y. H., Kim, H. K., Linthorst, H. J. M., Hollander, J. G., LeFeber, A. W. M., ERKenlens, C., NuZILlard, J.-M., and VERPOORTE, R. 2006. NMR metabolomics to revisit the tobacco mosaic virus infection in Nicotiana tabacum leaves. J. Nat. Prod. 69:742-748. doi:10.1021/np050535b.

Daniela, A., Pichichero, E., Canuti, L., Cicconi, R., Karou, D., D'Arcangelo, G., and CANinI, A. 2007. Identification of phenolic compounds from medicinal and melliferous plants and their cytotoxic activity in cancer cells. Caryologia 60:90-95.

De Boer, N. J. 1999. Pyrrolizidine alkaloid distribution in Senecio jacobaea rosettes minimises losses to generalist feeding. Entomol. Exp. Appl. 91:169-173. doi:10.1023/A:1003651801315.

De Jager, C. M., Butôt, R. P. T., Klinkhamer, P. G. L., De Jong, T. J., WolfF, K., and VAN Der Meidden, E. 1995a. Genetic variation in chrysanthemum for resistance to Frankliniella occidentalis. Entomol. Exp. Appl. 77:277-287. doi:10.1007/ BF02383062.

De Jager, C. M., Butôt, R. P. T., Klinkhamer, P. G. L., and Van Der MEIJDEN, E. 1995b. Chemical characteristics of chrysanthemum cause resistance to Frankliniella occidentalis (Thysanoptera: Thripidae). J. Econ. Entomol. 88:1746-1753.

De Jager, C. M., Butôt, R. P. T., VAn Der Meijden, E., and VERPOORTE, R. 1996. The role of primary and secondary metabolites in chrysanthemum resistance to Frankliniella occidentalis. J. Chem. Ecol. 22:1987-1999. doi:10.1007/ BF02040090.

DING, H., LAMB, R. J., and AMES, N. 2000. Inducible production of phenolic acids in wheat and antibiotic resistance to Sitodiplosis mosellana. J. Chem. Ecol. 26:969-985. doi:10.1023/ A:1005412309735.

EHMKe, A., VON BORSTEl, K., and HARTMAnN, T. 1988. Alkaloid Noxides as transport and vacuolar storage compounds of pyrrolizidine alkaloids in Senecio vulgaris L. Planta 176:83-90. doi:10.1007/BF00392483.

FRITZ, R. S. 1999. Resistance of hybrid plants to herbivore genes, environment or both. Ecology 80:382-391.

HäGELE, B. F., and Rowell-RAHIER, M. 2000. Choice, performance and heritability of performance of specialist and generalist insect herbivores towards cacalol and seneciphylline, two allelochemicals of Adenostyles alpine (Asteraceae). J. Evol. Biol. 13:131142. doi:10.1046/j.1420-9101.2000.00145.x.

HARTMANN, T., and ZIMMER, M. 1986. Organ-specific distribution and accumulation of pyrrolizidine alkaloids during the life-history of two annual Senecio species. J. Plant Physiol. 122:67-80.

Havlickova, H., CViKrova, M., and EDER, J. 1996. Phenolic acids in wheat cultivars in relation to plant suitability for and response to cereal aphids. J. Plant Dis. Prot. 103:535-542.

Hunter, W. B., and Ullman, D. E. 1989. Analysis of mouthpart movements during feeding of Frankliniella occidentalis (Pergande) and F. schultzei Trybom (Thysanoptera: Thripidae). Int. J. Insect Morphol. Embryol. 18:161-171. doi:10.1016/0020-7322 (89)90024-X.

Johnson, K. S., and Felton, G. W. 2001. Plant phenolics as dietary antioxidants for herbivorous insects: a test with genetically modified tobacco. J. Chem. Ecol. 27:2579-2597. doi:10.1023/ A: 1013691802028.

KIRK, W. D., and TERRY, I. 2003. The spread of the western flower thrips Frankliniella occidentalis (Pergande). Agric. For. Entomol. 5:301-310. doi:10.1046/j.1461-9563.2003.00192.x.

Kirk, H., ChOI, Y. H., Kim, H. K., Verpoorte, R., and VAN DeR MeIJdEN, E. 2005. Comparing metabolomes: the chemical consequences of hybridization in plants. New Phytol. 167:613622. doi:10.1111/j.1469-8137.2005.01448.x.

Lajide, L., Escoubas, P., and Mizutani, J. 1996. Cyclohexadienones-insect growth inhibitors from the foliar surface and tissue extracts of Senecio cannabifolius. Experientia 52:259-263. doi:10.1007/BF01920719.

Lattanzio, V., Arpaia, S., Cardinali, A., Di Venere, D., and LINSALATA, V. 2000. Role of endogenous flavanoids in resistance mechanism of Vigna to aphids. J. Agric. Food Chem. 48:53165320. doi:10.1021/jf000229y.

Lawton, J. H., and Brown, K. C. 1986. The population and community ecology of invading insects. Philos. Trans. R. Soc. Lond. B Biol. Sci. B314:607-617. doi:10.1098/rstb.1986.0076.

Le Gall, G., Dupont, M. S., Mellon, F. A., Davis, A. L., Collins, G. J., Verhoeyen, M. E., and Colquhoun, I. J. 2003. Characterization and content of flavonoid glycosides in genetically modified tomato (Lycopersicon esculentum) fruits. J. Agric. Food Chem. 51:2438-2446. doi:10.1021/jf025995e.

LI, Y. L., GAN, G. P., ZHANG, H. Z., WU, H. Z., LI, C. L., HuANG, Y. P., LIU, Y. W., and LIU, J. W. 2007. A flavonoid glycoside isolated from Smilax china L. rhizome in vitro anticancer effects on human cancer cell lines. J. Ethnopharmacol. 113:115-124. doi:10.1016/j.jep.2007.05.016.

Loizzo, M. R., Tundis, R., Statti, R., Statti, G. A., and Menichini, F. 2007. Jacaranone: a cytotoxic constituent from Senecio ambiguous subsp ambiguous (Biv) DC. against renal adenocarcinoma ACHN and prostate carcinoma LNCaP cells. Arch. Pharmacal. Res. 30:701-707. doi:10.1007/BF02977631. 
MACEL, M. 2003. On the evolution of the diversity of pyrrolizidine alkaloids. PhD Dissertation. University of Leiden.

Macel, M., Bruinsma, M., DiJkstra, S. M., OOIJEndiJK, T., NiemeYer, H. M., and KlinkHAmer, P. G. L. 2005. Differences in effects of pyrrolizidine alkaloids on five generalist insect herbivore species. J. Chem. Ecol. 31:1493-1508. doi:10.1007/ s10886-005-5793-0.

MallikarJuna, N., Kranthi, K. R., JadhaV, D. R., Kranthi, S., and CHANDRA, S. 2004. Influence of foliar chemical compounds on the development of Spodoptera litura (Fab.) in interspecific derivatives of groundnut. J. Appl. Entomol. 128:321-328. doi:10.1111/j.1439-0418.2004.00834.x.

MANTEL, W. P., and VAN DE VRIE, M. 1988. De californische trips, Frankliniella occidentalis, een nieuwe schadelijke tripssoort in de tuinbouw onder glas in Nederland. Entomol. Ber (Amsterdam) 48:140-144.

MaO, J. Q., Burt, A. J., Ramputh, A. I., Simmonds, J., Cass, L., Hubbard, K., Miller, S., AltosaAr, I., and Arnason, J. T. 2007. Diverted secondary metabolism and improved resistance to European corn borer (Ostrinia nubilalis) in maize (Zea mays L.) transformed with wheat oxalate oxidase. J. Agric. Food Chem. 55:2582-2589. doi:10.1021/jf063030f.

Maris, P. C., Joosten, N. N., Peters, D., and Goldbach, R. W. 2002. Thrips resistance in pepper and its consequences for the acquisition and inoculation of Tomato spotted wilt virus by the western flower thrips. Phytopathology 93:96-101. doi:10.1094/ PHYTO.2003.93.1.96.

MiLES, P. W., and OeRTLI, J. J. 1993. The significance of antioxidants in the aphid-plant interaction: the redox hypothesis. Entomol. Exp. Appl. 67:275-283. doi:10.1007/BF02383437.

OnYilagha, J. C., LAzorko, J., Gruber, M. Y., SOroka, J. J., and ERLANDSON, M. A. 2004. Effect of flavonoids on feeding preference and development of the crucifer pest Mamestra configurata Walker. J. Chem. Ecol. 30:109-124. doi:10.1023/B: JOEC.0000013185.62475.65.

ORIANS, C. M. 2000. The effects of hybridization in plants on secondary chemistry: implications for the ecology and evolution of plant-herbivore interactions. Am. J. Bot. 87:1749-1756. doi: $10.2307 / 2656824$.

Outchkourov, N. S., De Kogel, W. J., Schuurman-De Bruin, A., Abrahmson, M., and Jongsma, M. A. 2004a. Specific cysteine protease inhibitors act as deterrents of western flower thrips, Frankliniella occidentalis (Pergande), in transgenic potato. Plant Biotechnol. J. 2:439-448. doi:10.1111/j.14677652.2004.00088.x.

Outchkourov, N. S., De Kogel, W. J., Wiegers, G. L., AbrahMSON, M., and JONGSMA, M. A. 2004b. Engineered multidomain cysteine protease inhibitors yield resistance against western flower thrips (Frankliniella occidentalis) in greenhouse trials. Plant Biotechnol. J. 2:449-458. doi:10.1111/j.14677652.2004.00089.x.

Pieters, L. A. C., VAn Zoelen, A. M., VRieling, K., and Vlietinck, A. J. 1989. Determination of the pyrrolizidine alkaloids from Senecio jacobaea by ${ }^{1} \mathrm{H}$ and ${ }^{13} \mathrm{C}$ NMR spectroscopy. Mag. Res. Chem. 27:754-759. doi:10.1002/mrc.1260270808.

RIESEBERG, L. H., and ElLstRAND, N. C. 1993. What can molecular and morphological markers tell us about plant hybridization. Crit. Rev. Plant Sci. 12:213-241. doi:10.1080/713608045.

SaeEd, A. I., Sharov, V., White, J., Li, J., Liang, W., Bhagabati, N., Braisted, J., KLAPA, M., CURRIER, T., Thiagarajan, M., StURN, A., Snuffin, M., Rezantsev, A., Popov, D., Ryltsov, D., Kostukovich, E., Borisovsky, I., LIU, Z., VinsaVich, A., TRUSH, V., and QUACKENBUSH, J. 2003. TM4: a free, open-source system for microarray data management and analysis. Biotechniques 34:374-378.

SAntiago, R., Butron, A., Aranson, J. T., Reid, L. M., Souto, X. C., and Malvar, R. A. 2006. Putative role of pith cell wall phenylpropanoids in Sesamia nonagriodes (Lepidoptera: Noctuidae) resistance. J. Agric. Food Chem. 54:2274-2279. doi:10.1021/jf0524271.

Simmonds, M. S. J., and Stevenson, P. C. 2001. Effects of isoflavonoids from Cicer on larvae of Helicoverpa armigera. J. Chem. Ecol. 27:965-977. doi:10.1023/A:1010339104206.

SOKAL, R. R., and RoHLF, F. J. 1995. Biometry. 3rd edn. Freeman, New York.

Tsao, R., Marvin, C. H., Broadbent, A. B., Friesen, M., Allen, W. R., and McGarveY, B. D. 2005. Evidence for an isobutylamide associated with host-plant resistance to western flower thrips, Frankliniella occidentalis, in chrysanthemum. J. Chem. Ecol. 31:103-110. doi:10.1007/s10886-005-0977-1.

VAn Dam, N. M., Vuister, L. W. M., BergshoefF, C., De Vos, H., and VAn Der MeiJden, E. 1995. The 'raison d'être' of pyrrolizidine alkaloids in Cynoglossum officinale: deterrent effects against generalist herbivores. J. Chem. Ecol. 21:507523. doi:10.1007/BF02033698.

Van Dam, N. M., De Jong, T. J., Iwasa, Y., and Kubo, T. 1996. Optimal distribution of defences: are plant smart investors. Funct. Ecol. 10:128-136. doi:10.2307/2390271.

Van De Wetering, F., Hulshof, J., Posthuma, K., Harrewijn, P., GoldBACH, R., and PETERS, D. 1998. Distinct feeding behavior between sexes of Frankliniella occidentalis results in higher scar production and lower tospovirus transmission by females. Entomol. Exp. Appl. 88:9-15. doi:10.1023/A:1003201007855.

VerpoOrte, R., ChOI, Y. H., and KIM, H. K. 2007. NMR-based metabolomics at work in phytochemistry. Phytochem. Rev. 6:314. doi:10.1007/s11101-006-9031-3.

VRIELING, K., SoldaAt, L. L., and SMIT, W. 1991. The influence of pyrrolizidine alkaloids of Senecio jacobaea on Tyria jacobaea, Brachycaudus cardii and Haplothrips senecionis. Neth. J. Zool. 41:228-239. doi:10.1163/156854291X00162.

WANG, Y., CAI, Q. N., ZHANG, Q. W., and WAN, Y. 2006. Effect of the secondary substances from wheat on the growth and digestive physiology of cotton bollworm Helicoverpa armigera (Lepidoptera: Noctuidae). Eur. J. Entomol. 103:255-258.

Widarto, H. T., Van Der Meijden, E., Lefeber, A. W. M., ERKelens, C., Kim, H. K., Choi, Y. H., and Verpoorte, R. 2006. Metabolomic differentiation of Brassica rapa following herbivory by different insect instars using two dimensional nuclear magnetic resonance spectroscopy. J. Chem. Ecol 32:2417-2428. doi:10.1007/s10886-006-9152-6.

Witte, L., ERnst, L., Adam, H., and Hartmann, T. 1992. Chemotypes of two pyrrolizidine alkaloid-containing Sencio species. Phytochemistry 31:559-565. doi:10.1016/0031-9422 (92) $90038-\mathrm{R}$.

Wu, B., TAKahashi, T., Kashiwagi, T., Tebayashi, S.-I., and KiM, C.-S. 2007. New flavonoid glycosides from the leaves of Solidago altissima. Chem. Pharm. Bull. 55:815-816. doi:10.1248/ cpb.55.815.

Xu, H. H., Zhang, N. J., and CAsidA, J. E. 2003. Insecticides in Chinese medicinal plants: survey leading to jacaranone, a neurotoxicant and glutathione-reactive quinol. J. Agric. Food Chem. 51:2544-2547. doi:10.1021/jf021164x.

ZANGERL, A. R., and BAZZAZ, F. A. 1992. Theory and pattern in plant defense allocation, pp. 363-391, in R. S. FRITZ, and E. L. SIMMS (eds.). Plant Resistance to Herbivores and Pathogens. University of Chicago Press, Chicago. 